\title{
Shape recognition for ships: World War I naval camouflage under the magnifying glass
}

\author{
W. Bekers, R. De Meyer \& T. Strobbe \\ Department of Architecture and Urban Planning, \\ Ghent University, Belgium
}

\begin{abstract}
Much of the experiments that led to the development of World War I ship camouflage were conducted on an intuitive basis or based upon pseudo-scientific work. As a result of this rather empirical approach, possible effects of the naval camouflage schemes that were developed against the background of submarine warfare on the Atlantic still remain unclear. So-called dazzle paint schemes were conceived to break up target contours and disclose the ship's number, direction, speed and distance- thus complicating targeting through primitive stereoscopic range finders and periscopes used at the time. Digital image analysis provides helpful tools to assess the effects of dazzle painting techniques. By applying dazzle map textures to digital three dimensional models, different paint schemes can be examined and evaluated under variable atmospheric conditions. Shape recognition algorithms are implemented in an attempt to draw some conclusions about different dazzle designs. This paper provides a brief overview of the origins and methodology of dazzle camouflage. It proposes an experimental framework for ship classification purpose, thus exploring the possibilities of quantitative analysis of rendered computer images to evaluate possible effects of dazzle painting. The test results indicate some possible effects of the World War I paint schemes.
\end{abstract}

Keywords: camouflage, dazzle painting, image analysis, shape recognition, World War I, naval history. 


\section{Introduction}

During World War I, camouflage techniques take radical new directions and proportions. The organized disguising of men, equipment, infrastructure and even whole cities as to deceive the enemy about their exact contours or whereabouts can be considered as a direct reaction to rapidly evolving war technologies. More specifically, the introduction of aerial and submarine warfare paves the way for the development of odd camouflage strategies such as the creation of a full-scale faux Paris to mislead German bomber planes [1], or the development of bold, irregular camouflage patterns for ships, so called dazzle painting (fig. 1).

Much of the experiments leading towards the development of dazzle painting - and of World War I camouflage tactics in general-were conducted on an intuitive or pseudo-scientific basis. Research was mostly carried out by teams of artists following rather autonomous empirical trajectories, often relying on biologically inspired ideas on disruptive coloration [2]. Scientifically supported conclusions on the effects of dazzle painting are currently nonexistent. Research conducted right after World War I is contradictory in its conclusions and, in any case, confounding changes in convoy strategy and U-boat tactics that coincided with the adoption of dazzle painting make dissection of their relative influences impossible. The diverse nature of contributors demonstrates the hybrid and interdisciplinary character of the subject during its early years. Nonetheless, by the outbreak of the Second World War the whole conception of camouflage tactics and patterns had shifted from the realm of artists to that of researchers, engineers and architects; resulting in rationalization and standardization of naval camouflage [3].

Digital image analysis provides a helpful tool to evaluate the effects of dazzle painting techniques. When applying dazzle map textures to carefully rendered digital ship models, different paint schemes can be examined and evaluated. Three dimensional digital reconstructions are used here to overcome the absence of preserved camouflaged ships and the lack of color information in black and white photographs. Shape recognition algorithms can be put to use to draw

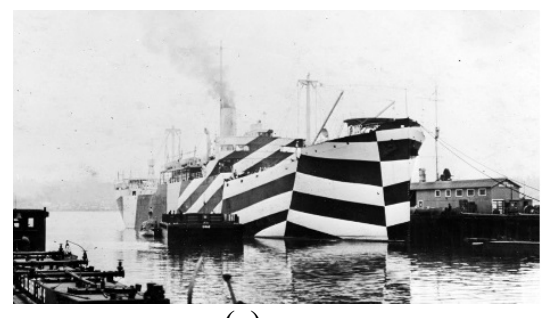

(a)

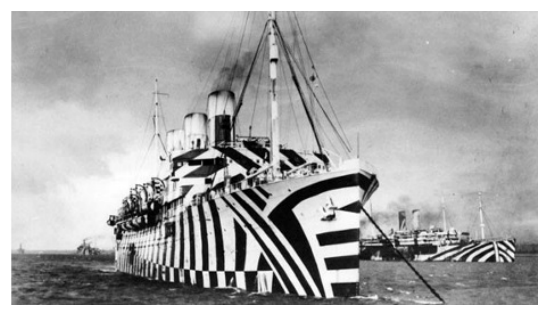

(b)

Figure 1: Examples of dazzle painted ships. (a) USS West Mahomet (Naval Library, Washington) and (b) SS Empress of Russia (Merseyside Museum, Liverpool). 
conclusions about different dazzle painting schemes. The idea to approach dazzle painting from the scope of image analysis of models in one sense emulates the evaluation process used during the war years, when painted ship models were tested on laboratory turntables and observed through periscopes and optical devices.

First, we will take a closer look at the origins and intentions of dazzle camouflage, followed by an overview of its design methodology. Next, we will explore in more detail how dazzle paint schemes on ships were tested and evaluated. We then proceed with the setup of an experiment, using shape recognition algorithms to evaluate three dimensional digital ship models in an attempt to draw some conclusions concerning the effects of dazzle painting on the concealment of ships. Finally, future and extended research possibilities are suggested.

\section{Naval camouflage in World War I}

\subsection{Origins of dazzle camouflage}

The outbreak of the Great War marks the invention of modern camouflage tactics, resulting in the establishment of a Section de Camouflage in the French army in 1915, soon followed by the other belligerents [4]. During the early war years, a strategy of low visibility for ships was commonly adopted by the British Royal Navy [5]. From 1903 on, warships were usually painted in uniform pale gray as this color was supposed to blend with the sea horizon in prevailing atmospheric conditions. As early as September 1914, zoologist Graham Kerr suggested to the British Admiralty the adoption of a camouflage system called parti-coloring, combining the principles of countershading for low visibility and disruptive patterns to break up the ship's contours [6]. He thereby followed biologically inspired ideas of American naturalist painters such as Abbott Handerson Thayer, whose findings on animal camouflage had been published in 1909 in the seminal book on the subject, titled Concealing-coloration in the Animal Kingdom [7]. This book abundantly illustrates the principles of countershading and disruptive camouflage in several stenciled images, experiments and mock-ups. Kerr's proposal, however, remained unaccepted.

Early 1917, with submarine warfare at its peak, excessive loss of allied shipping on the vital Atlantic routes and around the British Isles, forced the Admiralty to reconsider traditional concealing tactics. Naval painter-and Royal Navy Reserve Lieutenant-Norman Wilkinson proposed in April 1917 a camouflage scheme for ships that focuses on the relative short distances, crucial for torpedo aiming from a submarine periscope. In his vision, highly dynamic contexts with constantly shifting lighting and weather conditions, make the actual concealing of targets at sea an impossible task. Therefore, the goal of dazzle painting is to deceive the observer - rather than to conceal the target-by compromising the assessment of the ship's number, direction, speed and range [8]. Tests on the cargo ship Industry and SS War Shamrock in August 1917 proved successful in disturbing direction finding routines and torpedo 
preparation at distances of less than 1,000 meters. Using dazzle painting, the estimated chance for a torpedo hit could be reduced by 20 to 30 percent [5]. Shortly after, Wilkinson was appointed head of a new so called Dazzle Section. Other countries soon followed the British example. By November 1918, over 4,000 merchant vessels and 400 warships had been painted in unique dazzle paint patterns, in what might well be one of the largest artistic efforts of the war.

\subsection{Design methodology}

The design of dazzle paint schemes, as stated before, was based on artistic flair, empirical observation and intuition at first, but increasingly took on more systematical proportions. Still, some general principles were present from the very start, and would remain so throughout the war, be it in shifting order of importance as time evolved and depending on personal insights of the different designers $[5,9]$. Commonly used tactics are those of (1) countershading, (2) the illusion of false perspective, (3) the breaking up of masses and (4) the use of coloration.

First, countershading - or Thayer's Law - is derived from the zoological observation that animals have lighter pigments at the underside of their bodies and darker tints on the upper side. In Thayer's idea, this concept helps animals to blend in surrounding scenery when seen from above or below and also flattens out their silhouette when looked at from the side. This idea is translated in ship camouflage through the use of lighter shades on shadowed parts (such as undersides of overhanging parts, bow and stern) and darker shades on exposed areas.

Second, false perspectives are obtained by a variety of optical illusions, such as painting sterns and bows in lighter colors, creating fake sterns and bows at halfway lengths and adding a fake bow wave. Often, planar projections of boxes, distorted geometrical patterns and ship elements (or even complete ships) under awkward projection angles are used to mislead the observer on a ship's direction. Furthermore, these effects are increased by alterations to the ship's design itself, such as irregular smokestacks, symmetrical ship designs and eccentric placing of masts, smokestacks and superstructures.

Third, breaking up of masses is generally achieved by visually connecting the ship's superstructure to the hull, using large patches of darker colors that run from one volume into the other and around the corners. The same technique is usually applied to bow and stern. Using contrasting designs for port and starboard sides and providing as many designs as possible to avoid repetition, further adds to the deceit.

Finally, the use of color differs between the different dazzle design teams. In the United States, different systems are used and named after their inventors Mackay, Brush, Warner, Herzog and Toch [9]. They all have specific characteristics, but often use complementary colors, which are supposed to create dazzle effects on short distances, but blend into grey on the longer distance. At the British Dazzle Section, designs rather tend to evolve toward high-contrast black-and-white schemes (often complemented with patches of blue) in strong geometrical patterns [5]. 
It is hard to imagine bigger differences in camouflage concepts than those used on the French battlefields, aiming for background blending, and those used at sea, designed as highly conspicuous geometrical patterns.

\subsection{Testing platforms}

To test dazzle designs, Wilkinson's Dazzle Section used a relatively simple observation device with a boxed periscope at one end of a table and background sheets at the other side (fig. 2). Halfway the platform was a turntable for wooden ship models. Different dazzle designs would be applied on such models with removable paint. Atmospheric effects were simulated by placing more or less transparent screens in front of the periscope and by switching different background plates [5].

More advanced testing theatres were developed in the United States, containing artificial sky domes over water basins for solar studies, dynamic platforms for wave simulation and a periscope installed in a lorry on rails to simulate the approach of the observer to the targeted ship. An example of such an advanced testing platform was the one from the Boston District camouflage section. It used adjustable metal rolls covered with painted canvas to simulate different sea textures and wave conditions, nitrogen lamps for daylight simulation and a fog producing device consisting of mirrors and ground glass plates [10]. The construction of such platforms is worth mentioning, since they share an artificial setup that is quite similar to that the digital models that will be described in further sections.

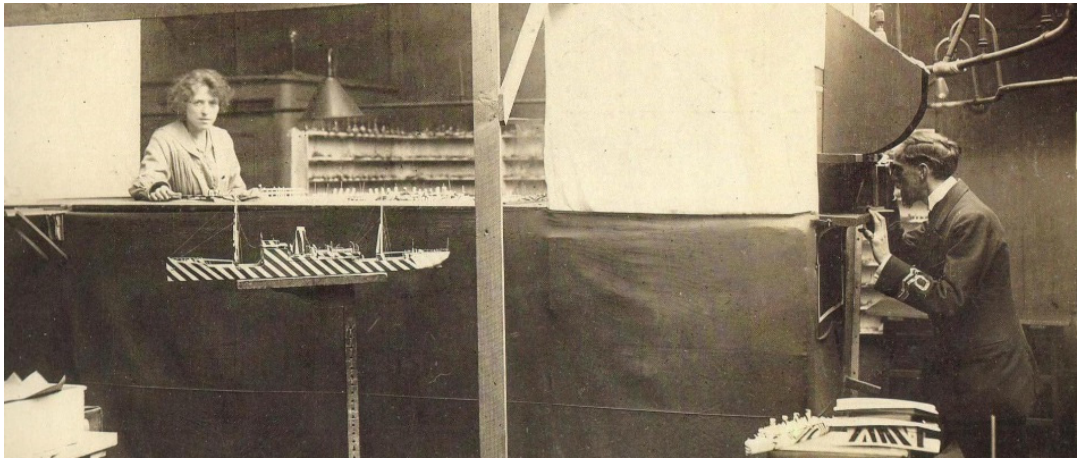

Figure 2: $\quad$ Testing theatre for dazzle designs (Rodney Wilkinson, New Milton).

\section{Effects of dazzle camouflage}

Possible military advantages of disruptive camouflage still remain unclear. Eyewitness reports from surface ship personnel and both British and captured German submarine commanders are contradictory. While some are deeply impressed by the optical illusions, others state that for normal range finding only masts and smokestacks are required, rendering the whole dazzle painting concept 
rather useless. In September 1918, a Committee on Dazzle Painting was established to investigate possible effects on the concealment of ships [11]. The committee concluded that there was no evidence of a single case in which the application of disruptive camouflage changed the event of an underwater torpedo attack by U-boats. However, the Committee strongly felt that there had been a certain increase in the confidence of ship crews sailing on painted ships. This suggests that the effect of dazzle painting was mainly a morale boost. The Committee also concluded that the influence of dazzle painting is hard to pinpoint, since its application coincided with the introduction of other tactical developments (such as the convoy system and zigzag maneuvering) and technical innovations (such as the use of hydrophones). It was even stated that under certain atmospheric conditions and when sailing in convoy, such camouflage could pose an increased risk to the painted ships.

One test from 1919, carried out by Leo S. Blodgett from the MIT department of Naval Architecture, deserves more attention, because it is probably the only scientific research on the subject that has been carried out at the time relying on quantitative research methods [10]. Blodgett tested twelve ship models with different horizon settings on the Boston testing platform as described earlier. $\mathrm{He}$ used three sets of observers - with different experience and involvement in dazzle design - to gather statistical data on course estimation errors for the different designs. He obtained average angle estimation errors of around $20^{\circ}$ to $30^{\circ}$. The relative low amount of statistical data makes it hard to draw general conclusions from this research. However, it might be useful as a benchmark when comparing the results to contemporary research.

\section{Digital image analysis of dazzle painting}

\subsection{Related research}

Recent research in the domains of zoology and perceptual psychology indicates some relevant effects of disruptive camouflage on shape interpretation and speed estimation $[12,13]$. Those experiments rely on human observation of computer generated animations and images. However, the question if those conclusions can be extrapolated to painted ships, remains unanswered.

Recent large strides in the domain of machine learning and computer vision facilitated the implementation of shape recognition in various scientific domains, going as far as morphological classification of large datasets of galaxy images [14]. Pattern recognition and computer vision were first applied to dazzle camouflage by social artist Adam Harvey. His project CV Dazzle [15] demonstrates how makeup and hairstyles based upon World War I ship camouflage principles are able to disturb and confuse automated face recognition on social network sites.

\subsection{Overview of the experiment}

The goal of the following experiment is to set up a workflow that can be used to produce a large amount of statistical data concerning the effects of dazzle 
painting, thus bypassing the setbacks of the research as carried out in 1919 [10]. An interdisciplinary method is applied, using techniques from digital 3D modeling and visualization, digital image processing and machine learning.

The first step is the creation of three dimensional digital ship models that can be textured and lit to meet historical dazzle patterns and photorealistic atmospheric conditions. The rendered and normalized output of those models is then pre-processed making use of open source libraries for digital image analysis (Open CV). The result of this analysis is fed into learning algorithms that have been trained in advance for specific shape recognition purposes, in this case ship classification. By feeding different sets of data into the algorithm (ships with and without dazzle painting, sets of invalid images), different solution spaces are plotted to see if a difference can be perceived between the different test sets.

\subsection{Selection of dazzle designs}

At this moment, the described setup has been tested on two ship models. The selection of the ship models depends on a number of parameters. The first one is the availability of full sets of plans and dazzle schemes, so that a satisfactory historical ship model can be created. The second one is the availability of multiple dazzle schemes for the chosen ship class, so that the experiment, in future, can easily be expanded towards more dazzle typologies and the ship's design itself can be ruled out as a determinative factor in the recognition algorithm. The third parameter is a differentiation in ship type. We choose a small Royal Navy warship and a large US Navy transport ship (fig. 3). Both ships were constructed in the same period and put into service in the last war years.

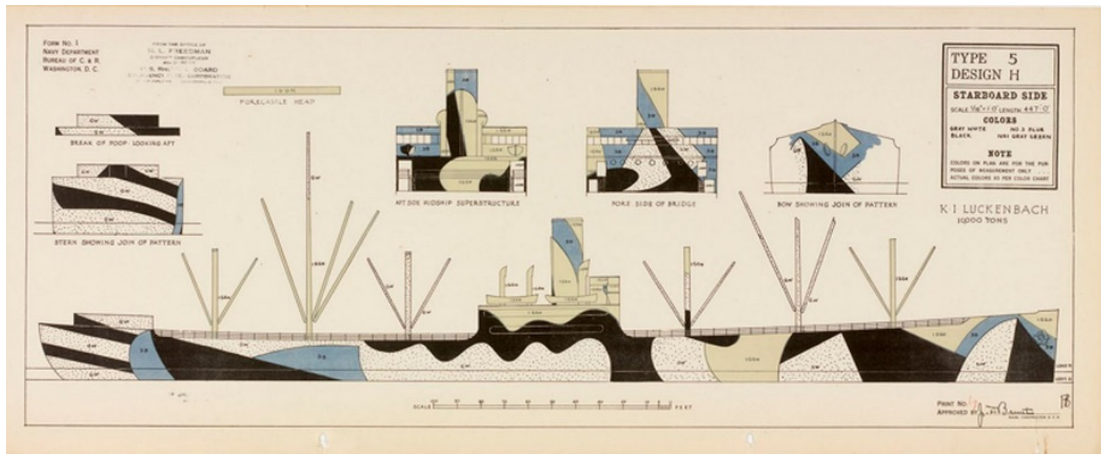

Figure 3: USS K.I. Luckenbach. Starboard dazzle design (Rhode Island School of Design, Providence).

The first ship is HMS Ormonde, an 81 meter long minesweeping sloop of the 24-class, launched in June 1918 by the Royal Navy. This ship class was designed to have the appearance of a cargo ship. Moreover, the design is symmetrical, using only one central mast and a bow-like stern, as to create confusion about the ship's direction. The second ship is USS K.I. Luckenbach, a commercial cargo vessel from the Luckenbach Steamship Company, launched in 1917, but acquired 
by US Navy in August 1918. It served as a supply ship for the American Expeditionary Force in France and, after the armistice, as a troop transport ship to return soldiers back home.

\subsection{Creation of three dimensional digital models}

Three dimensional models were set up, using conventional modeling techniques. Ship hulls were modeled in Rhinoceros 5.0. Textures, dynamic waves, backgrounds and atmospheric effects were created in 3ds Max Design 2014, using the V-Ray 3.0 for 3ds Max plug-in.

The colors of the texture maps are derived from color charts reconstructed from Wilkinson's own article on ship camouflage in Encyclopaedia Britannica [16] and from Blodgett's color chart of US Navy standard color schemes [10]. Textures are created with a matte paint effect, as was used to minimize specular reflection. For both test ships, versions with and without dazzle painting have been created. The models are set up for different sea, weather and lighting conditions, allowing for an enormous variety of different environment settings (fig. 4). For this experiment, following parameters were controlled: visibility (through the use of environmental fog), ship distance to observer, wave height and intensity, background and solar settings. Camera settings are adjustable to meet actual periscope magnification and aspect ratio standards.

\subsection{Shape recognition}

The actual shape recognition algorithm is at this point a three-step process. The first step uses SURF (Speeded-Up Robust Features) to detect key points and certain regions of interest on one bitmap image, using a cascade of image analysis tools like edge-finding, blob detection and so on. Next, a BOW (Bag of Words) model is used to represent the images. This concept is derived from text analysis, in which a text is represented as a "bag" of keywords, without a specific ordering. In computer vision, an image can also be described as a bag of key points or "visual words". This allows for the construction of a visual vocabulary of image fragment types or features that can be used for classification purposes. The third step in this chain is the use of SVM (Support Vector Machine), a set of machine learning algorithms that attempt to classify data based on similarity or difference $[17,18]$.

In this case, a set of 132 images has been used as training samples (fig. 5). These training pictures show different early twentieth century ships, seen from as many angles as possible. To compensate for the lack of color images, the training set has been expanded with color drawings, postcards and present day renderings from computer games. To cover all possible viewing angles, rendered images of both non-camouflaged test ships have also been included in the training set, however in smaller amounts ( 20 images of each model). The adding of computer generated images to the training set should also blur undesired effects resulting from differences between photographic and rendered images. 

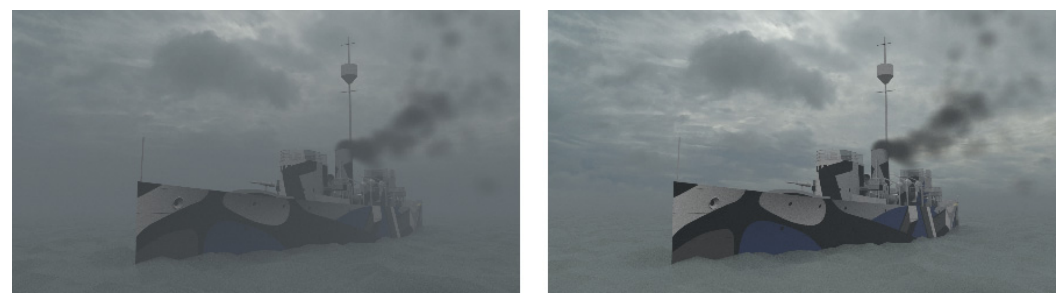

(a)
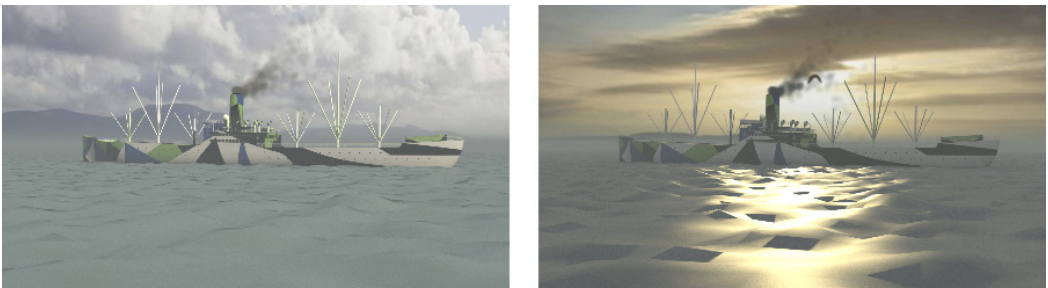

(b)
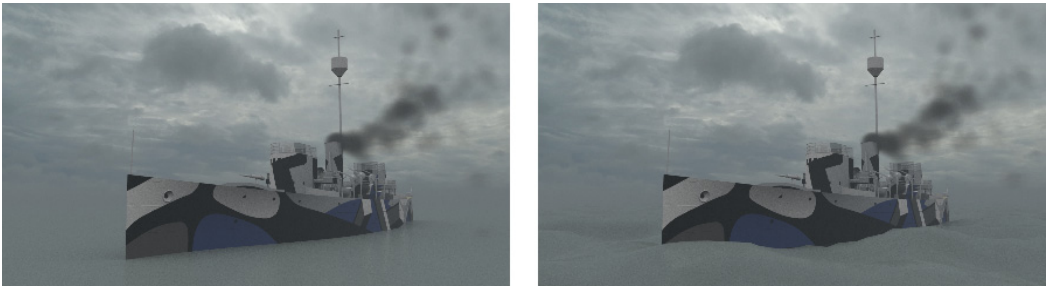

(c)
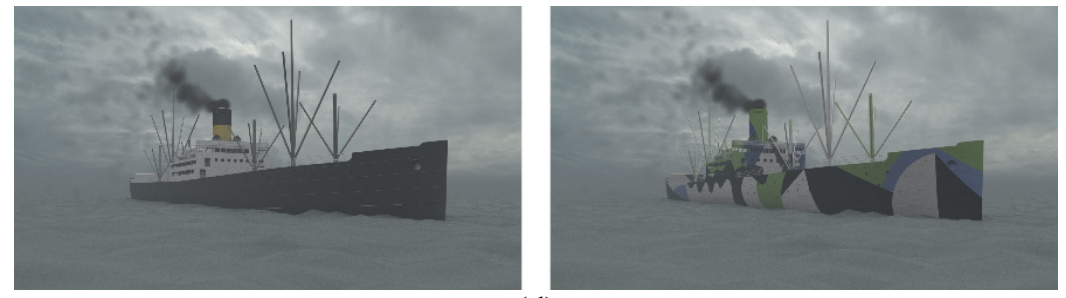

(d)

Figure 4: $\quad$ Rendered model samples, showing controllable parameters: (a) fog and visibility; (b) background and lighting; (c) wave height and frequency; (d) dazzle pattern.
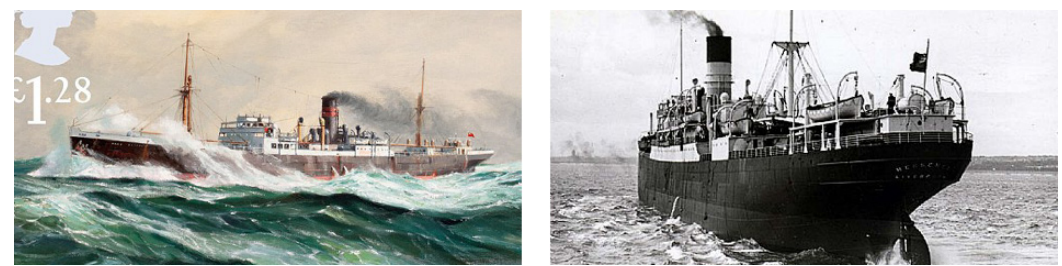

Figure 5: Random samples from training set.

WIT Transactions on The Built Environment, Vol 158, (C) 2016 WIT Press www.witpress.com, ISSN 1743-3509 (on-line) 


\subsection{Results}

A first run resulted in an accuracy of $68 \%$ for detecting ships in random images. This accuracy rate can further be increased if more valid training data are supplied. A final test was carried out comparing a similar test set of 20 images for both test ships, with and without dazzle painting, in bright weather circumstances (figs 6 and 7). The results show an accuracy of $72 \%$ in recognizing ships without dazzle painting, versus only $56 \%$ for the test set with dazzle painting. This indicates a significant, or promising at least, difference in the abilities of the algorithm to recognize ships without camouflage easier. When the environment settings were adjusted to an overcast sky and fog, the test results for camouflaged and non-camouflaged ships, seemed to converge, which might indicate that low visibility diminishes the effects of dazzle painting.

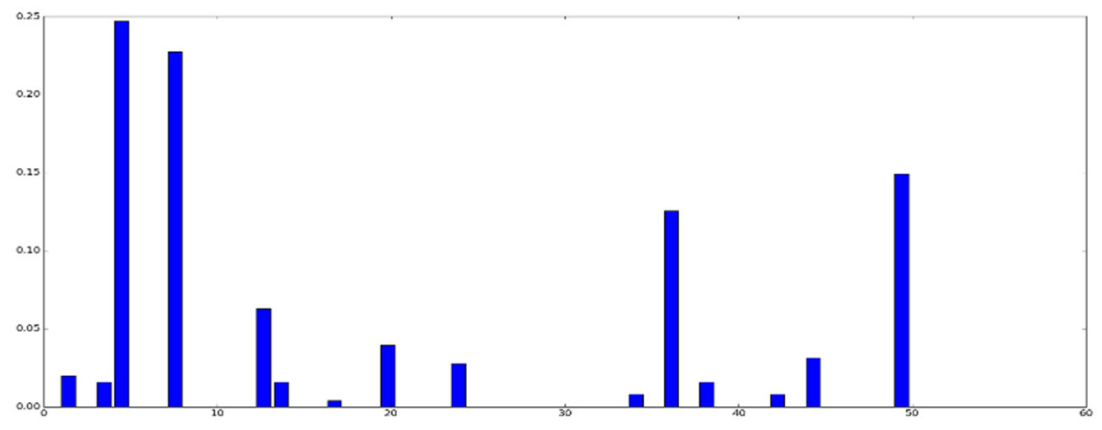

Figure 6: Typical histogram of analyzed image.

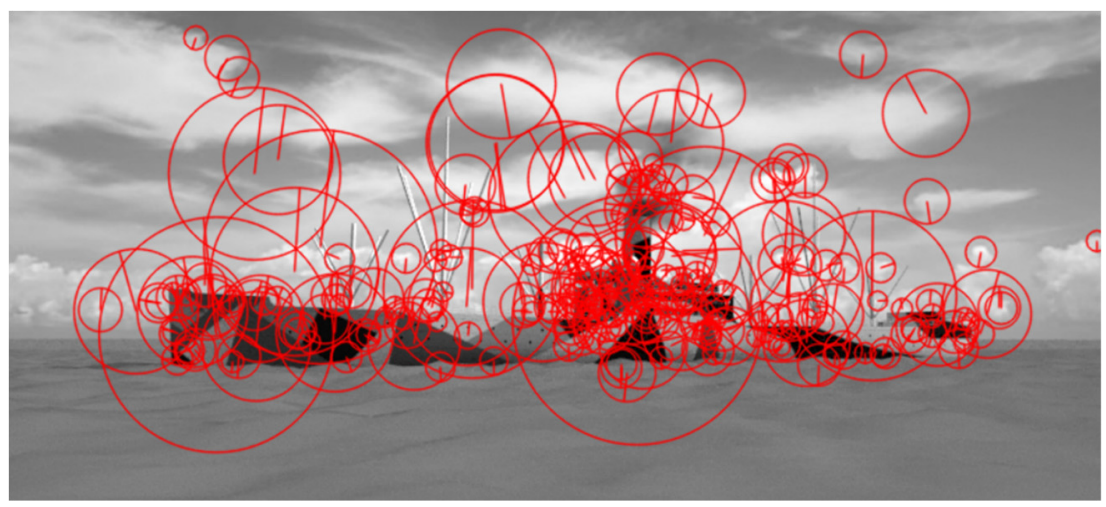

Figure 7: Example of feature detection on rendered model. 


\section{Conclusions}

The most important result of the experiment is the indication that it is possible to use shape recognition algorithms for ship detection on rendered ship models. When considering the results, it is important to note that at this moment, a relative small amount of training samples has been used. A significant larger training set can result in a higher accuracy rate. An up and running workflow has been created that can relatively easily been enhanced and expanded by adding more samples.

Second, the first tests seem to confirm the results of the 1919 research in its conclusion that a certain effect of dazzle painting can be derived from quantitative research. This effect is visible in the result-but it is far from overwhelming and only occurs under certain atmospheric circumstances. A wider variety of atmospheric tests is needed here to confirm these first results and pinpoint the influence of different parameters. The easy adjustment of such properties in digital models offers obvious advantages, compared to the evaluation of abstracted wooden models on analog testing platforms in 1919.

Third, the use of three dimensional models, apart from delivering interesting visual material for wider audiences, proves invaluable when analyzing dazzle patterns, compared to the sterile orthographic projections of the camouflage plans, or wartime black and white photographs. When looked at under certain angles, they offer direct visual reference on the methods used in dazzle painting design.

At this point, it might be worthwhile to pinpoint possible expansions of this research. In the field of machine learning, it is obvious that the recognition of ships by itself is insufficient to draw hard conclusions on the effects of dazzle painting. To do so, shape detection should be able to estimate course and distance of a ship, since disrupting those two parameters, direction and distance, was eventually the goal of any dazzle painting scheme. From the viewpoint of shape recognition, it is obvious that a larger amount of samples can generate sufficient data to exclude other influencing parameters. Implementing state-ofthe-art machine learning methods, such as neural networks, would undoubtedly increase the accurate predictions of the model. This would require a considerable amount of human observational data to generate an initial set of reliably annotated images that can be integrated in the training phase of the neural networks, thus taking in account typical bias of human observation [14].

In a wider context, the proposed method, as a final conclusion, might also prove beneficial to related domains where quantitative research on historical image datasets (original or, as in this case, reconstructed) would generate an added value (e.g. interpretation of aerial photographs, analysis of architectural drawings, shape detection on paintings, tracing landscape relicts).

\section{References}

[1] Boissel, X., Paris est un leurre. La véritable histoire du faux Paris, Éditions Inculte: Paris, 2012. 
[2] Behrens, R. R., The role of artists in ship camouflage during World War I. Leonardo, 32(1), pp. 53-59, 1999.

[3] Cohen, J.-L. \& Zardini, M., Camouflage, or the temptation of the invisible. Architecture in Uniform. Designing and Building for the Second World War, Éditions Hazan: Paris, pp. 187-219, 2011.

[4] Coutin, C., Tromper l'ennemi: L' invention du camouflage moderne en 1914-1918, Éditions Pierre de Taillac et Ministère de la Défense: Paris, 2012.

[5] Roskam, A., Dazzle Painting: Kunst als Camouflage, Camouflage als Kunst, Stichting Kunstprojecten en Uitgeverij Van Spijk: Venlo, 1987.

[6] Murphy, H., \& Bellamy, M., The dazzling zoologist: John Graham Kerr and the early development of ship camouflage. The Northern Mariner, 19(2), pp. 171-192, 2009.

[7] Thayer, G. H., Concealing Coloration in the Animal Kingdom: An Exposition of the Laws of Disguise Through Color and Pattern: Being a Summary of Abbott H. Thayer's Discoveries, Macmillan: New York, 1909.

[8] Wilkinson, N., Dazzle painting of ships. The Nautical Gazette, p. 177, 13 September 1919.

[9] Behrens, R. R., Ship Shape, a Dazzle Camouflage Sourcebook: an Anthology of Writings about Ship Camouflage during World War I, Bobolink Books: Dysart, Iowa, 2012.

[10] Blodgett, L. S., Ship Camouflage, M.S. Thesis, Department of Naval Architecture and Marine Engineering, Massachusetts Institute of Technology, Cambridge, 1919.

[11] Report of the Committee on Dazzle Painting, Reference MT 25/16. The National Archives, Kew, London, 1918.

[12] Stevens, M., Yule, D. H. \& Ruxton, and G. D., Dazzle coloration and prey movement, Proceedings of the Royal Society, 275, August 2008.

[13] Scott-Samuel, N., Baddely, R., \& Palmer, C. E. \& Cuthill, I. C., Dazzle camouflage affects speed perception. PLoSOne, 6(6), 2011.

[14] Dieleman, S., Willett, K. W., Dambre, J., Rotation-invariant convolutional neural networks for galaxy morphology prediction. Monthly notices of the royal astronomical society, 450(2), pp. 1441-1459, 2015.

[15] Harvey, A., CV Dazzle, Creative Commons, 2010, Online. http://www.cvdazzle.com. [Accessed 7 December 2014].

[16] Wilkinson, N., Naval camouflage, Encyclopaedia Britannica $12^{\text {th }}$ Edition, 1, pp. 546-547, 1922.

[17] Csurka, G., Dance, C. R., Fan, L., Willamowski, J., Bray, C., Visual categorization with bags of keypoints. ECCV'04 Workshop on Statistical Learning in Computer Vision, pp. 59-74, 2004.

[18] Nowak, E., Jurie, F., Triggs, B, Sampling strategies for bag-of-features image classification. ECCV 2006, Pt. 4 Proceeding, eds. Leonardis, A, Bischof, H., Pinz, A., Springer Verlag: Heidelberg, pp. 490-503, 2006. 